\title{
PREVALENCE OF OVERWEIGHT AND OBESITY AMONG 5 - 16 YEARS IN SEMI-URBAN AREAS OF COIMBATORE, INDIA
}

\author{
Rajendran Nambi Krishnan', Gopimohan Ramachandran², Balasubramanian Sivasankaran ${ }^{3}$
}

${ }^{1}$ Associate Professor, Department of Paediatrics, Karpagam Faculty of Medical Sciences and Research, Coimbatore, Tamilnadu. ${ }^{2}$ Assistant Professor, Department of Paediatrics, Travancore Medical College, Thattamala, Kerala.

${ }^{3}$ Assistant Professor, Department of Biochemistry, Dr. N.G.P. Arts and Science College, Coimbatore, Tamilnadu.

\section{ABSTRACT}

\section{BACKGROUND}

Majority of studies on childhood obesity and overweight are done in affluent school children. Therefore, in this study we measured the prevalence rate of overweight and obesity in children from semi-urban area of Coimbatore city. We compared the BMI profile of our sample with revised IAP growth chart.

\section{MATERIALS AND METHODS}

About 1781 healthy children from semi-urban areas are selected from the age group between 5 - 16 years who visited this charitable hospital for immunisation and school health check-ups during the study period from January 2015 to August 2016. Their correct age, weight and height measured using the standard recommended methods and BMI calculated. The collected data are analysed using the latest version of SPSS.

\section{RESULTS}

Our study conducted in children from semi-urban area of Coimbatore city has found that the prevalence of overweight is at $12.8 \%$ and obesity is at $5.8 \%$. However, nearly $7.5 \%$ of the studied population is in the underweight category.

\section{CONCLUSION}

The prevalence rate of overweight and obesity observed in our study population from semi-urban area of Coimbatore city is lesser than the studies from affluent setting. However, sizable portion of our study population is coming under underweight category. Therefore, malnutrition is still a big public health problem in spite of changing lifestyle.

\section{KEYWORDS}

Body Mass Index (BMI), Semi-Urban Children, Coimbatore, India and Revised IAP Growth Chart.

HOW TO CITE THIS ARTICLE: Krishnan RN, Ramachandran G, Sivasankaran B. Prevalence of overweight and obesity among 5 - 16 years in semi-urban areas of Coimbatore, India. J. Evolution Med. Dent. Sci. 2017;6(19):1524-1528, D0I: 10.14260/Jemds/2017/335

\section{BACKGROUND}

Childhood obesity is one of the most serious public health challenges of $21^{\text {st }}$ century. Earlier, it was a major health problem of children in developed countries and in families of high socioeconomic status in developing countries. Now, it has also become a common health concern of developing countries including India, ${ }^{1}$ where increasing proportion of overweight and obese children are seen in urban and semi-urban areas. ${ }^{2}$ In 2013, obese children worldwide is estimated at 42 million. Currently, over 15 million children are estimated to be overweight in India. If the current trend continues, over 70 million children and adolescents will be overweight by 2025.3 According to the report appeared in Times of India, India is the $3^{\text {rd }}$ most obese country in the world. Overweight and obese children are likely to stay obese into their adulthood. Thereby, these children are more vulnerable to develop health risks concerning non-communicable diseases such as type-2 diabetes, hypertension, cardiovascular diseases,

Financial or Other, Competing Interest: None.

Submission 24-01-2017, Peer Review 19-02-2017,

Acceptance 25-02-2017, Published 06-03-2017.

Corresponding Author:

Dr. Balasubramanian Sivasankaran,

Assistant Professor,

Department of Biochemistry,

Dr. N.G.P. Arts and Science College,

Coimbatore-641048, Tamilnadu, India.

E-mail: sbala0410@gmail.com

DOI: $10.14260 /$ jemds $/ 2017 / 335$

(c) $(1) \ominus$ hyperlipidaemia and arthritis, comparatively sooner in their lifetime.

The Body Mass Index (BMI) is a measure that defines overweight and obesity in children and adolescents. Universally, overweight is defined as the BMI at or above $85^{\text {th }}$ percentile and below 95th percentile for children and adolescents of similar age and sex. Children with BMI of more than $95^{\text {th }}$ percentile for a given age and sex are obese. ${ }^{3}$ The Centres for Disease Control (CDC) groups the weight categories of growing children and adolescents based on the BMI percentile. The BMI below 18.5 is considered underweight, while the BMI between 18.5 and 24.9 comes under normal category. The BMI between 25 and 29.9 is overweight, and the BMI of 30.0 and above is categorised as obese. 4 This BMI based grouping cannot be uniform across the race and nations as people of Indian sub-continent are known to have more adiposity and increased cardio-metabolic risk at a lower BMI, therefore it varies. Utilising the BMI grouping that is standardised in a population of different country might give erroneous census in the Indian context.5,6,7 Therefore, the Growth Chart Committee (GCC) of Indian Academy of Paediatrics (IAP) recommends a revised growth chart for Indian children and adolescents. Based on that, the adult equivalent cut-off lines at the BMI of 23 and 27 is considered as the risk of overweight and obesity respectively in Indian children and adolescents. ${ }^{8,9,10}$ In this study, we measured the BMI values of our selected population (Children and adolescents) and compared it with BMI values of IAP-201511 to determine the prevalence rate of overweight and obesity 
among children and adolescents coming from semi-urban areas of Coimbatore in the state of Tamilnadu.

\section{MATERIALS AND METHODS}

This was a cross-sectional study done at Shanthi Social Services (SSS), a multispeciality hospital treating mainly the poor people. This health facility has located in the Eastern periphery of Coimbatore city in the state of Tamilnadu. The total duration of the study was 18 months (Jan' 2015 to Aug 2016). After thorough discussion on the objective and methodology, Director of the Hospital had given permission to conduct the study. Children of low socio-economic group visiting outpatient department of the hospital from nearby areas were our study population. Only healthy children and adolescents from 5 to 16 years' age group were included in the study. Children with serious sickness, chronic malnutrition, bone and other congenital anomalies, serious endocrine disorders were excluded from the study. A full demographic data including weight and height were collected from 1781 (Children and adolescents) participants through standard established procedure. ${ }^{6}$ The weight was taken on an electronic weighing machine with $10 \mathrm{gm}$ sensitivity. The weight was recorded according to the standard procedure with minimal clothing and without chappals. The height of participants was measured using the wall mounted fixed rolling in centimetre tape, which shows height in meters in a square window. The height was taken when the child was standing close and the heel, buttocks, back and head were straightened against the wall. The head end of the rod was brought down and pressed over the hair. ${ }^{7}$ The BMI was calculated by the formula: $\mathrm{BMI}=$ Weight $(\mathrm{kg}) /$ height $\left(\mathrm{m}^{2}\right)$. The calculated BMI were compared with revised IAP BMI growth references. The data were analysed using the latest version of SPSS software.

\section{RESULTS}

A total of 1781 children and adolescents who had fulfilled the inclusion criteria of the study were included in the final analysis (Table 1). Among them, 55\% (982) were boys and the remaining 45\% (799) were girls. The age group of study participants were ranged from 5 to 16 years (Table 1). Statistically, reasonable number of participants were available for age groups starting from 5 to 13 years. Thereafter, the total number of participants were small for each age group. More than 200 (ranged between 201 and 239) participants were available for the age groups between 5 and 8 years with a distribution range of $11.3 \%$ to $13.4 \%$ (Table 1 ). In the age groups of 9 to 13 years, more than 100 individuals had participated in the study with a distribution of range of $7.1 \%$ to $9.9 \%$. For the remaining age groups of 14,15 and 16 years, the total number of participating individuals were numerically smaller and their distribution percentages ranged between $0.6 \%$ and $3.8 \%$ (Table 1 ).

\begin{tabular}{|c|c|c|}
\hline \multirow{2}{*}{ Characteristics } & Participants & Distribution \\
\cline { 2 - 3 } & $(\mathbf{\%})$ \\
\hline 1. Gender & & \\
\hline Boys (B) & 982 & 55 \\
\hline Girls (G) & 799 & 45 \\
\hline 2. Age & Total (B + G) & \\
\hline 05 Years & $216(125+091)$ & 12.2 \\
\hline 06 Years & $239(124+115)$ & 13.4 \\
\hline 07 Years & $222(115+107)$ & 12.5 \\
\hline 08 Years & $201(098+103)$ & 11.3 \\
\hline 09 Years & $177(092+085)$ & 9.9 \\
\hline
\end{tabular}

\begin{tabular}{|c|c|c|}
\hline 10 Years & $177(091+086)$ & 9.9 \\
\hline 11 Years & $143(092+051)$ & 8 \\
\hline 12 Years & $161(094+067)$ & 9 \\
\hline 13 Years & $127(080+047)$ & 7.1 \\
\hline 14 Years & $067(041+026)$ & 3.8 \\
\hline 15 Years & $040(024+016)$ & 2.3 \\
\hline 16 Years & $011(006+005)$ & 0.6 \\
\hline \multicolumn{2}{|c|}{ Table 1. Population Demographics } \\
\hline
\end{tabular}

The anthropometric measurements in boys had a steady growth in mean height and a rapid gain in mean weight. Boys from the age of 5 and until 10 had a rapid growth in their mean height (108.1 to $134.1 \mathrm{~cm}$ ) (Table 2). Whereas, incremental growth in mean height had been only in the age groups of 11 to 16 years ( 140.1 to $161.0 \mathrm{~cm}$ ) (Table 2). However, the mean weight gain was slow in the age group of 5 to 10 years (16.8 to $28.6 \mathrm{~kg}$ ). Thereafter, the mean weight gain was rapid in all age groups studied (32.3 to $55.5 \mathrm{~kg}$ ) (Table 2).

Similarly, anthropometric measurements in girls had a steady growth in mean height and gradual gain in mean weight (Table 3). Girls from the age of 5 and until 10 had an incremental growth in their mean height (108 to $133.3 \mathrm{~cm}$ ). Thereafter, a rapid rise in mean height was noted in the age groups from 11 to 16 years ( 128.3 to $155.6 \mathrm{~cm}$ ) (Table 3). The mean weight gain in girls also followed the similar trend observed in boys. The mean weight in 5-year-old was at 16.3 $\mathrm{kg}$, while it reached to $27.5 \mathrm{~kg}$ in 10-year-old. Appropriate weight gain was observed from the age of 11 years onwards. It was ranged from 32.6 to $50.8 \mathrm{~kg}$ for 11 years to 16 years of age (Table 3).

\begin{tabular}{|c|c|c|c|}
\hline Age (Years) & Height (cm) & Weight (kg) & BMI (kg/m²) \\
\hline (Boys) & $\begin{array}{c}\text { (Mean } \\
\pm \text { STD) }\end{array}$ & $\begin{array}{c}\text { (Mean } \\
\pm \text { STD) }\end{array}$ & (Mean \pm STD) \\
\hline $05(125)$ & $108.1 \pm 6.6$ & $16.8 \pm 3.1$ & $14.3 \pm 1.3$ \\
\hline $06(124)$ & $114.1 \pm 7.6$ & $18.8 \pm 3.8$ & $14.4 \pm 2.0$ \\
\hline $07(115)$ & $119.5 \pm 6.8$ & $21.0 \pm 4.4$ & $14.6 \pm 2.2$ \\
\hline $08(098)$ & $126.8 \pm 6.4$ & $24.2 \pm 5.5$ & $14.9 \pm 2.5$ \\
\hline $09(092)$ & $130.9 \pm 8.2$ & $27.4 \pm 7.7$ & $15.8 \pm 3.1$ \\
\hline $10(091)$ & $134.1 \pm 7.0$ & $28.6 \pm 7.3$ & $15.8 \pm 3.2$ \\
\hline $11(092)$ & $140.1 \pm 8.3$ & $32.3 \pm 8.5$ & $16.4 \pm 3.2$ \\
\hline $12(094)$ & $143.8 \pm 8.6$ & $34.7 \pm 10.1$ & $16.6 \pm 3.8$ \\
\hline $13(080)$ & $148.0 \pm 11.9$ & $38.6 \pm 9.6$ & $17.5 \pm 3.3$ \\
\hline $14(041)$ & $155.0 \pm 7.9$ & $41.8 \pm 11.3$ & $17.3 \pm 4.2$ \\
\hline $15(024)$ & $154.6 \pm 8.0$ & $41.4 \pm 12.2$ & $17.1 \pm 4.1$ \\
\hline $16(006)$ & $161.0 \pm 8.4$ & $55.3 \pm 7.3$ & $21.4 \pm 2.8$ \\
\hline
\end{tabular}

Table 2. Anthropometric Measurements (Boys)

\begin{tabular}{|c|c|c|c|}
\hline Age (Years) & Height (cm) & Weight (kg) & BMI (kg/m $\mathbf{m}^{\mathbf{}}$ ) \\
\hline (Girls) & (Mean \pm STD) & (Mean \pm STD) & (Mean \pm STD) \\
\hline $05(091)$ & $108.0 \pm 7.6$ & $16.3 \pm 2.5$ & $13.9 \pm 1.4$ \\
\hline $06(115)$ & $112.7 \pm 7.0$ & $18.7 \pm 4.5$ & $14.6 \pm 2.5$ \\
\hline $07(107)$ & $118.9 \pm 6.7$ & $21.0 \pm 4.6$ & $14.7 \pm 2.2$ \\
\hline $08(103)$ & $123.8 \pm 6.5$ & $22.7 \pm 5.0$ & $14.7 \pm 2.4$ \\
\hline $09(085)$ & $128.3 \pm 7.9$ & $24.6 \pm 5.3$ & $14.8 \pm 2.1$ \\
\hline $10(086)$ & $133.3 \pm 7.8$ & $27.5 \pm 6.8$ & $15.4 \pm 2.9$ \\
\hline $11(051)$ & $139.1 \pm 7.0$ & $32.6 \pm 8.2$ & $16.7 \pm 3.4$ \\
\hline $12(067)$ & $142.4 \pm 9.2$ & $36.2 \pm 9.5$ & $17.7 \pm 3.7$ \\
\hline $13(047)$ & $148.5 \pm 7.3$ & $38.8 \pm 11.2$ & $17.5 \pm 4.5$ \\
\hline $14(026)$ & $151.4 \pm 6.8$ & $42.0 \pm 8.6$ & $18.2 \pm 3.1$ \\
\hline $15(016)$ & $151.9 \pm 3.5$ & $41.5 \pm 4.4$ & $18.0 \pm 1.9$ \\
\hline $16(005)$ & $155.6 \pm 5.2$ & $50.8 \pm 10.6$ & $21.0 \pm 4.3$ \\
\hline \multicolumn{4}{|c|}{ Table 3. Anthropometric Measurements (Girls) } \\
\hline
\end{tabular}


The distribution of mean BMI values among boys from the age of 5 to 16 years were shown in Table 4. Our measured BMI value across age groups were displayed along with the revised IAP BMI cut-off at 23 and 27, an adult equivalent respectively of overweight and obese for comparison (Table 4). In all age groups, there was at least a less of 1 to $2.5 \mathrm{BMI}$ differences observed in the study population in comparison to an adult equivalent cut-off at 23 that determines overweight and more so for the cut-off at 27 for obese (Table 4). For 5-year-old the BMI value was 14.3, while IAP 23 and IAP 27 adult equivalents were 15.7 and 17.5 respectively. Similarly, the BMI for $6,7,8$, 9 and 10 years old were in the range of 14.4 to 15.8 , whereas the IAP BMI cut-off for 23 was ranged between 16.0 and 18.0 and for 27 it ranged between 17.8 and 20.5. Similar trend in BMI was also observed for the age groups of $11,12,13,14,15$ and 16 years old (Table 4 ).

\begin{tabular}{|c|c|c|c|}
\hline \multirow{4}{*}{$\begin{array}{c}\text { Age (Years) } \\
\text { (Boys) }\end{array}$} & Present Study & Revised IAP & Revised IAP \\
\hline & BMI $\left(\mathrm{kg} / \mathrm{m}^{2}\right)$ & BMI-23 & BMI-27 \\
\hline & & $\begin{array}{c}\text { Adult } \\
\text { Equivalent }\end{array}$ & \begin{tabular}{|c|} 
Adult \\
Equivalent
\end{tabular} \\
\hline & & (Overweight) & (Obese) \\
\hline $05(125)$ & 14.3 & 15.7 & 17.5 \\
\hline $06(124)$ & 14.4 & 16 & 17.8 \\
\hline 07 (115) & 14.6 & 16.3 & 18.2 \\
\hline $08(098)$ & 14.9 & 16.7 & 18.8 \\
\hline $09(092)$ & 15.8 & 17.3 & 19.6 \\
\hline $10(091)$ & 15.8 & 18 & 20.5 \\
\hline $11(092)$ & 16.4 & 18.7 & 21.5 \\
\hline $12(094)$ & 16.6 & 19.5 & 22.6 \\
\hline $13(080)$ & 17.5 & 20.2 & 23.4 \\
\hline $14(041)$ & 17.3 & 20.8 & 24.2 \\
\hline $15(024)$ & 17.1 & 21.4 & 24.9 \\
\hline $16(006)$ & 21.4 & 22 & 25.5 \\
\hline
\end{tabular}

Table 4. BMI of Boys in Comparison with Revised IAP

Percentile Values at 23 and 27 Adult Equivalents

Table 5 depicts the distribution of mean BMI values of girls from the age of 5 to 16 years. Our measured mean BMI values were displayed along with IAP reference BMI cut-off at 23 and 27 , an adult equivalent respectively determining overweight and obese categories (Table 5). Across age groups, there was at least a less of 1 to $2.5 \mathrm{BMI}$ differences observed in the study population in comparison to an adult equivalent cut-off at 23 that determines overweight and more so for the cut-off at 27 for obese (Table 5). For 5-year-old girls the mean BMI was 13.9, while IAP BMI 23 and IAP BMI 27 adult equivalents were 15.5 and 18.0 respectively (Table 5). Similarly, the mean BMI for $6,7,8,9$ and 10 years old were in the range of 14.6 to 15.4 , whereas the IAP BMI cut-off for 23 was ranged between 15.9 and 18.4 and for 27 was ranged between 18.6 and 21.9. Similar trend in BMI was also observed for the age groups of 11,12 , 13, 14, 15 and 16 years old (Table 5).

The prevalent rate of overweight and obese boys in our population was shown in Table 6. In this study population, boys with overweight had ranged between 7.3 to $16.7 \%$. In the age groups of 5- and 6-year-old boys, the incidence of overweight was at around $10 \%$. From 7 years of age and up to 13 years, we had seen a moderate increase in the overweight population. Though incidence rate was similar in 14 - 16 years' age group, the sample size was smaller to arrive at a conclusion (Table 6). In the case of obesity, the incidence rate in boys ranged between 3.2 and $16.7 \%$. This rate was around
$5 \%$ in 5, 6 and 7 years of age. This rate had rapidly increased to $10.2 \%$ and $12 \%$ in 8 - and 9-year-old boys respectively. Following this increase, the rate stayed around $7-10 \%$ in remaining age groups of boys with the exception of 16 years old (Table 6). In total, $11.8 \%$ and $7.3 \%$ of boys in our population were overweight and obese respectively.

\begin{tabular}{|c|c|c|c|}
\hline \multirow{3}{*}{$\begin{array}{c}\text { Age (Years) } \\
\text { (Girls) }\end{array}$} & Present Study & Revised IAP & Revised IAP \\
\hline & BMI $\left(\mathrm{kg} / \mathrm{m}^{2}\right)$ & BMI-23 & BMI-27 \\
\hline & & $\begin{array}{c}\text { Adult } \\
\text { Equivalent }\end{array}$ & $\begin{array}{c}\text { Adult } \\
\text { Equivalent }\end{array}$ \\
\hline & & (Overweight) & (Obese) \\
\hline $05(091)$ & 13.9 & 15.5 & 18 \\
\hline $06(115)$ & 14.6 & 15.9 & 18.6 \\
\hline 07 (107) & 14.7 & 16.4 & 19.3 \\
\hline $08(103)$ & 14.7 & 16.9 & 20.1 \\
\hline $09(085)$ & 14.8 & 17.6 & 21 \\
\hline $10(086)$ & 15.4 & 18.4 & 21.9 \\
\hline $11(051)$ & 16.7 & 19.3 & 23 \\
\hline $12(067)$ & 17.7 & 20.2 & 24.1 \\
\hline $13(047)$ & 17.5 & 21.1 & 25.2 \\
\hline $14(026)$ & 18.2 & 21.8 & 25.9 \\
\hline $15(016)$ & 18 & 22.3 & 26.3 \\
\hline $16(005)$ & 21 & 22.6 & 26.5 \\
\hline
\end{tabular}

The prevalent rate of overweight and obese girls in our population was shown in Table 7. In this study population, girls with overweight had ranged between 9.4 to $22.3 \%$. In all age groups, overweight incidence rate was approximately similar across age groups (Table 7). In comparison to boys, girls had at least 2 - 4\% increase in incidence rate of overweight for a similar age. The obesity incidence rate in girls ranged between 1.1 and $8.7 \%$. However, the rate did not show any rapid changes across age group and did not follow any pattern. Incidentally, in some age groups, there were no obese girls at all (Table 7). In total, $13.8 \%$ and $4.3 \%$ of girls in our population were overweight and obese respectively.

\begin{tabular}{|c|c|c|}
\hline Boys Age & & \\
\hline (Years) (n) & Overweight \% (n) & Obese \% (n) \\
\hline $05(125)$ & $9.6(12)$ & $3.2(04)$ \\
\hline $06(124)$ & $8.9(11)$ & $5.7(07)$ \\
\hline 07 (115) & $14.8(17)$ & $5.2(06)$ \\
\hline $08(098)$ & $11.2(11)$ & $10.2(10)$ \\
\hline 09 (092) & $15.1(14)$ & $12.0(11)$ \\
\hline $10(091)$ & $13.2(12)$ & $7.7(07)$ \\
\hline $11(092)$ & $15.2(14)$ & $7.6(07)$ \\
\hline $12(094)$ & $10.6(10)$ & $7.5(07)$ \\
\hline $13(080)$ & $11.3(09)$ & $7.5(06)$ \\
\hline $14(041)$ & $7.3(03)$ & $9.8(04)$ \\
\hline $15(024)$ & $8.3(02)$ & $8.3(02)$ \\
\hline $16(006)$ & $16.7(01)$ & $16.7(01)$ \\
\hline Total 982 & $11.8(116)$ & $7.3(72)$ \\
\hline \multicolumn{3}{|c|}{$\begin{array}{l}\text { Table 6. Distribution of Overweight and } \\
\text { Obese Boys in Our Study Population }\end{array}$} \\
\hline
\end{tabular}




\begin{tabular}{|c|c|c|}
\hline Girls Age & & \\
\hline (Years) (n) & Overweight \% (n) & Obese \% (n) \\
\hline $05(091)$ & $13.2(12)$ & $1.1(01)$ \\
\hline $06(115)$ & $14.0(16)$ & $8.7(10)$ \\
\hline 07 (107) & $15.9(17)$ & $4.7(05)$ \\
\hline $08(103)$ & $12.6(13)$ & $3.9(04)$ \\
\hline $09(085)$ & $9.4(08)$ & --- \\
\hline $10(086)$ & $11.6(10)$ & $4.7(04)$ \\
\hline $11(051)$ & $15.7(08)$ & $7.8(04)$ \\
\hline $12(067)$ & $22.3(15)$ & $6.0(04)$ \\
\hline $13(047)$ & $10.6(05)$ & $4.3(02)$ \\
\hline $14(026)$ & $15.4(04)$ & - \\
\hline $15(016)$ & - & - \\
\hline $16(005)$ & $40.0(02)$ & - \\
\hline Total 799 & $13.8(110)$ & $4.3(34)$ \\
\hline $\begin{array}{r}\text { Tab } \\
\text { and } 01\end{array}$ & $\begin{array}{l}\text { istribution of Ov } \\
\text { irls in Our Study }\end{array}$ & $\begin{array}{l}\text { ght } \\
\text { lation }\end{array}$ \\
\hline
\end{tabular}

\section{DISCUSSION}

There is a paucity of well-conducted studies, and lack of uniformity in the age and sex specific cut-off points used to define overweight and obesity nationally. As a result, the magnitude of overweight and obesity problem in India especially between 5 - 18 years of age is relatively unclear. 5 Therefore, examining our children using the nationally collected growth data sets must become a mandatory practice as the BMI calculation based on WHO/NCHS recommendations may mislead the veracity of problem.6,12 Especially, when the BMI cut-off to define overweight and obesity in our adult population starts at lower scale in comparison to Western population. In response, IAP has created a nation specific BMI chart for children and adolescents ( 5 - 18 years old) of both sexes. ${ }^{5}$

The problem of overweight and obesity is increasing in Indian children, especially in urban areas. ${ }^{13}$ In a recent systematic review, study based on pooled data found an increasing trend of overweight and obesity problem also in lower income groups. ${ }^{9}$ Therefore, we have selected our study population from semi-urban areas assuming that it might reflect both income (High and Low) groups. Among the total 1781 children in our study, $12.8 \%$ and $5.8 \%$ are respectively the population representing overweight and obesity category. When the data is segregated based on the sex, $11.8 \%$ and $7.3 \%$ boys respectively are overweight and obese, while girls are also following similar trend at $13.8 \%$ and $4.3 \%$ respectively for overweight and obese category. Prevalence of overweight population in our study for both sexes is nearly twice the rate observed by Laxmaiah et al, where the rate in boys is at $6.1 \%$ while in girls is at $8.2 \% .^{13}$ Moreover, both studies have observed similar trend in incremental BMI increase in adolescents compared to children. Young girls in our study started off with lower BMI in comparison to boys and reached higher than boys in their adolescent period. This rapid weight gain can be ascertained to early puberty attainment and reduced physical activity in girls. A study done in Chennai has observed high overall prevalence of obesity in urban children, and more importantly higher in girls than boys. ${ }^{14}$ Similar observation are also observed in a study from Bhubaneswar where $45.2 \%$ of private school children and $10.5 \%$ of government school children are overweight/obese. ${ }^{8}$ However, a study by Khadilkar put overweight/obesity prevalence rate in children from private school at $26.4 \%$ and government school at $14.6 \%$. They have reasoned increasing sedentary lifestyle among students during their educational period, especially related to modern recreational activities and high calorie dietary habits to this observed changes. ${ }^{15}$ These transformations have affected even children from the semiurban and rural areas. ${ }^{9}$

From all studies including ours, we see the influence of changes in lifestyle on the increasing tendency in overweight and obesity incidence rate even in semi-urban population. Earlier studies have shown higher prevalence of overweight and obesity problems in urban India. However, ours is the first study to put the prevalence rate of overweight/obesity at around $20 \%$ in semi-urban areas of Coimbatore and it is highly significant. This weight gain will be an important health issue when these children reach adulthood. Therefore, vigorous measures are to be undertaken immediately through national programmes to arrest further deterioration in health due to overweight/obesity, and bring down to lower level and eradicate it. The important steps that can be taken to increase health awareness among public are curb down high-calorie fast foods, strict laws to prohibit the indoor electronic games, and encourage outdoor play and games among children.

\section{CONCLUSION}

The limitations of our study are two-fold, where total sample size in certain age category is lesser and samplings are from one semi-urban part of the city. Additionally, our study at this stage has not collected data pertaining to nutritional status, socioeconomic status and complete clinical evaluation of children. Therefore, there is an urgency for larger study that should include children from all peripheral areas of the city and collect complete data sets. This approach should be extended nationally to develop an inclusive growth chart for children from urban, semi-urban and rural India. Thereby, the new chart might be used not only to ascertain the prevalence rate of overweight/obesity among children and adolescents but also to predict future trajectory of the problem.

\section{REFERENCES}

[1] Laxmaiah A, Nagalla B, Vijayaraghavan K, et al. Factors Affecting Prevalence of Overweight Among 12- to 17year-old Urban Adolescents in Hyderabad, India. Obesity 2007;15(6):1384-90.

[2] Childhood overweight and obesity. WHO 2016.

[3] Commission on ending childhood obesity. WHO 2016. ISBN 9789241510066.

[4] Navaneetham P, Kalaivani T, Rajasekaran C, et al. Nutritional status of children in rural India: a case study from Tamil Nadu, first in the world to initiate the MidDay Meal scheme. Health 2011;3(10):647-55.

[5] Khadilkar V, Yadav S, Agrawal KK, et al. Revised IAP growth charts for height, weight and body mass index for 5-18 years old Indian Children. Indian Pediatrics 2015;52:47-55.

[6] Khadilkar VV, Khadilkar AV, Cole TJ, et al. Cross sectional growth curves for height, weight and body mass index for affluent Indian Children, 2007. Indian Pediatr 2009;46(6):477-89.

[7] Kliegman RM, Behrman RE, Jenson HB, et al. Nutrition. Part 6, Chapter 4. In: Nelson text book of paediatrics. $20^{\text {th }}$ edn. 2016:pgs- 298, 286, 307. 
[8] Khadilkar VV, Khadilkar AV, Borade AB. Body mass index cut-offs for screening for childhood overweight and obesity in Indian children. Indian Pediatrics 2012;49(1):29-34.

[9] Patnaik L, Pattanaik S, Sahu T, et al. Overweight and obesity among adolescents- a comparative study between government and private schools. Indian Pediatrics 2015;52(9):779-81.

[10] Ranjani H, Mehreen TS, Pradeepa R, et al. Epidemiology of childhood overweight \& obesity in India: a systematic review. Indian J Med Res 2016;143(2):16074.

[11] Jagadesan S, Harish R, Miranda P, et al. Prevalence of overweight and obesity among school children and adolescents in Chennai. Indian Pediatr 2014;51(7):544-9.
[12] Parthasarathy A. IAP textbook of paediatrics. $5^{\text {th }}$ edn. Jaypee Brothers Medical Publishers (P) Ltd 2013:p-77.

[13] Veetus S, Shivaprakash NC. The study of blood pressure profile and body Mass Index among children in a rural setting. IJBR 2014;5(4):244-6.

[14] Kumaravel V, Shriraam V, Anitharani M, et al. Are the current Indian growth charts really representative? Analysis of anthropometric assessment of school children in a South Indian District. Indian J Endocrinol Metab 2014;18(1):56-62.

[15] Siddiqui NI. Prevalence and trends of obesity in Indian school children of different socioeconomic class. Indian Journal of Basic and Applied Medical Research 2012;2(5):393-8. 